\author{
Joanna Partyka \\ Instytut Badań Literackich PAN, Warszawa \\ joanna.partyka@ibl.waw.pl \\ Julia Lewandowska ${ }^{1}$ \\ Instytut Badań Literackich PAN, Warszawa \\ j.lewandowska@al.uw.edu.pl
}

\title{
Jak pisać o pisarkach? Podsumowania
}

\begin{abstract}
How do you write about female authors?

At the moment, the majority of papers concerning women's writing oscillates between cultural studies and literary studies, or history studies and literary studies.
\end{abstract}

1 Omawianą $\mathrm{w}$ tym artykule problematatykę Julia Lewandowska rozwija szerzej w rozprawie doktorskiej: Escritoras monjas: Autoridad y autoría en la escritura conventual femenina de los Siglos de Oro, poświęconej zagadnieniu kobiecych pisarek związanych ze środowiskiem wczesnonowożytnych klasztorów żeńskich w Hiszpanii. W swoim ujęciu badawczym proponuje tzw. perspektywę dialogiczną jako odpowiedź na problem adekwatnej metodologii do badań nad twórczością literacką kobiecego autorstwa powstałą w wiekach dawnych. Perspektywa ta jest próbą znalezienia nowego stanowiska, sytuującego się pomiędzy analizą historiograficzną, a ujęciem dialogicznym literackiej krytyki feministycznej; ma na uwadze wielość i różnorodność kontekstów kształtujących każdą wypowiedź i pozwala na zrozumienie jej zarówno na płaszczyźnie praktyk twórczych w danym kontekście społeczno-kulturowym i historycznym, jak i tradycji literackiej z uwzględnieniem znaczenia i wpływu płci/gender (płci kulturowej) na kształtowanie się podmiotu (w tym podmiotu piszącego) i relacji społecznych, w ramach których tworzy. 
Such a view on women's creative output and, in more general terms, women's presence in culture, seems to bring the best results. Due to academic development in recent decades and the so-called "return of the subject" in philosophical, social, historical and literary studies, these disciplines gained a perspective that turns to womanly experiences, and interprets them with specific methodologies, thereby rendering them valid objects of study and representative voices of a given epoch.

In studies on early modern women's literature, we should create a space for dialogue between philological studies, social history, the history of culture and gender studies. Only such an attitude makes it possible to avoid misunderstandings inscribed in the studies on early modern culture carried out with the application of modern and post-modern analytical categories, including the category of gender. At the same time, we should bear in mind that gender always remains a category that is useful in historico-literary analyses, if it keeps its critical relation to binary categories "woman"/"man" and "femininity"/"masculinity", as well as to its own function consisting of forming social dynamics based on the sexual difference. Thus understood dialogical perspective allows going beyond the programmatic and methodological frames of feminist studies, in which a "woman" and a "man" are presented as permanent and closed categories that can only be used to describe various social roles, but do not lead to any critical interpretation of these roles.

Key words: feminist literary criticism, gender, women's writing

Elaine Showalter w 1981 roku przypomniała „wyrażoną kiedyś obawę” Matthew Arnolda, że „krytycy literaccy mogą zejść na bezdroża, zanim zdołają dotrzeć do ziemi obiecanej neutralności”, i dodaje, że „bezdroża teorii, jakie rozpościerają się pomiędzy feministyczną ideologią a liberalnym ideałem neutralności [...], muszą zostać oswojone"2. Podążając za Ardenerowskim³ modelem ukazującym relacje pomiędzy grupą dominującą a grupą pozbawioną głosu [ $\mathrm{mu}$ -

2 E. Showalter, Krytyka feministyczna na bezdrożach. Pluralizm a krytyka feministyczna, „Teksty Drugie”,nr 4/5/6 (22/23/24) (1993), s. 115-116.

3 Shirley i Edwin Ardenerowie nakreślili model kulturowej sytuacji kobiet w Belief and the Problem of Women (1972) i The Problem Revisited (1975). Poprzez wskazanie na powiązania języka i władzy model ten stał się użytecznym punktem odniesienia dla feministycznej teorii literatury i kultury. Oprócz Showalter nawią- 
ted], amerykańska badaczka zaproponowała wyjście od kulturowo zorientowanej krytyki literackiej jako tej, która pozwala na możliwie najpełniejszy ogląd kobiecego pisarstwa - obejmujący zagadnienie ciała, języka i psychiki oraz sytuujący je w ramach społecznych i historycznych kontekstów. W jej rozumieniu pożądana neutralność jest fantazmatem, bowiem „ziemią obiecaną [krytyki feministycznej] nie jest sielsko niezróżnicowana uniwersalność tekstów, lecz burzliwe i intrygujące ostępy odmienności”" Jedynie poprzez zrozumienie owej odmienności jako dwugłosowej, czyli zawierającej się w ramach dyskursu dominującego, a jednocześnie posiadającej obszar „dziki”, nienazywalny językiem logosu, możliwe jest ujęcie kobiecego pisarstwa poza kategoriami esencjalizmu i rewizjonizmu.

Badania podejmowane obecnie w Polsce, poruszające takie aspekty kobiecej obecności w historii i kulturze jak wykształcenie, czytelnictwo, twórczość/pisarstwo kobiet i ich udział w mecenacie literackim i artystycznym nowożytnej Rzeczpospolitej, wydają się już dostatecznie ugruntowane. $Z$ roku na rok otrzymujemy nowe, pogłębione studia, które przekonują (lub prawie przekonują), że: (1) we wczesnonowożytnej Rzeczpospolitej kobiety miały podobny (a nie gorszy i nie zdecydowanie lepszy, jak jeszcze niedawno usiłowano dowodzić) status społeczny jak w całej Europie, (2) kształcenie kobiet na poziomie podstawowym i średnim (do wyższego nie miały dostępu) wyglądało podobnie jak w całej Europie, z zastrzeżeniem, że protestanci przywiązywali większą wagę do ich kształcenia z powodów praktycznych, (3) kobiet piszących, a zwłaszcza publikujących było zdecydowanie mniej w Rzeczpospolitej niż w krajach takich jak Anglia, Italia, Francja czy Hiszpania - im głębiej w wiek XVIII, tym było ich jednak więcej, (4) o biernym i czynnym uczestnictwie kobiet w życiu kulturalnym Rzeczypospolitej należy mówić i pisać bez jakichkolwiek kompleksów.

zywały do niego również inne badaczki jak np. Sandra Gilbert i Susan Gubar (1979, 1991), Cheric Kramarae (1989), Dale Spender (1984), Julia Penelope (1990).

4 E. Showalter, Krytyka feministyczna na bezdrożach..., s. 146. 
Obecnie nikt już nie przeczy oczywistemu faktowi, że kobiece pisarstwo, a nawet kobiece zwykłe pisanie przez wieki spotykało się z podejrzliwością, jeśli nie wyraźną niechęcią. Tak było zresztą z niemalże każdą aktywnością kobiet wykraczającą poza przypisane im tradycyjnie role społeczne. Pomimo to pozytywne refleksje na temat literackiej i artystycznej twórczości kobiet pojawiają się niemalże równocześnie z głosami krytyki, choć dziś trudniej do nich dotrzeć. Mamy wiele - ba, coraz więcej - dowodów na to, że „męskie uprzedzenia" nie były w stanie unicestwić kobiecych ambicji. Może dlatego, że mężczyźni nie byli konsekwentni w swoich przekonaniach i od czasu do czasu głosom antyfeministycznym przeciwstawiano traktaty-katalogi pełne pochwał uczonych niewiast.

Obecnie nie tworzy się już legend, lecz się z nimi walczy. W XIX wieku Jan Sowiński rozbrajająco przyznawał, że w poszukiwaniu pisarek dość swobodnie interpretował znaleziony materiał staropolski: „Niektóre Polek dzieła - pisze - wyszły bez oznaczenia nazwisk autorek, lecz że to powszechnie są nam znane, nie zdawało mi się konieczną rzeczą ukrywać ich imiona. Potomność, jeżeli to pismo dojdzie do niej, nie będzie miała trudności w dochodzeniu onych"5. Sowiński nie uznawał za stosowne, by weryfikować owe powszechne sądy, do jego katalogu uczonych Polek trafily zatem także pisarki wyimaginowane ${ }^{6}$. „Potomność” najpierw bezkrytycznie powtarzała ustalenia Sowińskiego, by po dwóch niemalże wiekach je weryfikować.

Showalter postulowała, by badać kobiety ,j a ko pisarzy, czyniąc przedmiotem swych rozważań: historię, style, tematy, gatunki i struktury pisarstwa kobiecego, a także psychodynamikę kobiecej twórczości, przebieg indywidualnej bądź grupowej kobiecej kariery oraz ewolucję i normy kobiecej tradycji literackiej"”. Proponowała

5 J. Sowiński, O uczonych Polkach, Warszawa 1821, Przedmowa, s. iv.

6 Por. J. Partyka, Żona wyćwiczona. Kobieta piszaca w kulturze XVI i XVII wieku, Warszawa 2004, s. 9-29.

7 E. Showalter, Krytyka feministyczna na bezdrożach..., s. 122. 
rewindykację zastąpić reorientacją. Reprezentująca krytykę feministyczną Inga Iwasiów ${ }^{8}$ krytykuje „klasyczne studia kobiece”, które „mają na celu odtworzenie historii kobiet i historii literatury kobiet, zrewidowanie i rewindykowanie zastanej tradycji, o której myślimy jako o wykluczającej podmioty kobiece, limitującej normy, ograniczającej reprezentację”; " "udomowienie» kobiet to banał” - pisze dalej ${ }^{9}$. Dla badaczy dawnych epok interesujące jest także następujące spostrzeżenie polskiej literaturoznawczyni: „Czytane z perspektywy zastanej wiedzy, w kontekście obowiązujących kanonów interpretacyjnych utwory z dawnych epok [...] pozwalają zobaczyć, kim nie była w przeszłości kobieta - pisarka, bohaterka, czytelniczka, a kim byłaby, gdyby jej losy potoczyły się inaczej" ${ }^{10}$. Ta konstatacja przywodzi na myśl wykreowaną przez Virginię Woolf we Własnym pokoju siostrę Szekspira, Judith, tyle że w krzywym zwierciadle. Judith dorównywała talentem bratu, była zdolna i ambitna. Przygotowywano ją jednak do pełnienia innej roli w społeczeństwie - miała przykładnie wyjść za mąż i wziąć na siebie obowiązki żony i gospodyni, a nie zaśmiecać sobie głowę książkami. Chcąc walczyć o swoje marzenia, uciekła z domu. Środowisko, w którym pragnęła zaistnieć, poniżyło ją i wyśmiało. Talent zmarnował się: niedoszła aktorka i dramatopisarka pozbawiła się życia ${ }^{11}$.

Inga Iwasiów obawia się, że „Studia kobiece sięgają obecnie punktu krytycznego: coraz bardziej są culture studies, coraz mniej literaturoznawstwem”. „Studia gender - uważa - powinny [...] wrócić do pytań literaturoznawczych i poetologicznych. Można zadać ponownie pytania o gatunki, o poetyki, o instancje - właśnie dlatego, że wykonany został zwrot kulturoznawczy. Nie warto jednak pozostać na zawsze w obszarze culture studies, bowiem jedyną formą nie-

8 I. Iwasiów, Wstęp, do: Prywatne/publiczne. Gatunki pisarstwa kobiecego, red. I. Iwasiów, Szczecin 2008, s. 7-11.

9 Ibidem, s. 7.

10 Ibidem, s. 8.

11 Por. V. Woolf, Własny pokój, przeł. A. Graff, wstęp I. Filipiak, Warszawa 1997, s. 68-69. 
istnienia literatury jest jej porzucenie, zaniechanie czytania, zapomnienie teorii. Pożytki mogą w ten sposób zamienić się w klęski”"12. Nie zapominajmy jednak o culture studies, które przynoszą inne spostrzeżenia na temat kobiecej obecności w kulturze, dopełniając te literaturoznawcze. Obecnie większość polskich opracowań książek i artykułów - podejmujących kwestie kobiecego pisarstwa oscyluje pomiędzy studiami kulturowymi i literaturoznawstwem oraz historią i literaturoznawstwem. Taki ogląd kobiecej twórczości - i ogólniej: kobiecej obecności w kulturze - wydaje się przynosić najlepsze rezultaty.

Oprócz odzyskania i/lub ponownego odczytania głosów i doświadczeń kobiet wieków dawnych - co nas tu najbardziej interesuje - krytyka literacka spod znaku badań feministycznych umożliwiła postawienie pytań zarówno o kondycje autorek jako podmiotów ucieleśnionych, posiadających płeć kulturową (gendered), jak i o dynamikę „wytwarzania i odtwarzania kobiecości normatywnej”, by posłużyć się sformowaniem hiszpańskiej badaczki Celii Amorós ${ }^{13}$. Otworzyły się dzięki temu nowe przestrzenie dla opisu i interpretacji kobiecej twórczości. Według Françoise Collin, filozofki i feministki belgijskiej, kluczowym osiągnięciem badaczek historii kobiet i krytyczek kobiecej literatury było już samo nazwanie autorek tworzących w wiekach dawnych, co jest niezwykle znamienne ${ }^{14}$. Owo „przywrócenie imienia” stanowi dziś najbardziej namacalne dokonanie badań kobiecych (women's studies) i fundament, na którym można już uzupełniać badania tradycji literackich, praktyk kulturowych i myśli estetycznej, włączając perspektywę i doświadczenia kobiet. Stanowisko, jakie przyjęła podczas tzw. drugiej fali feminizmu ginokrytyka, pozostaje o tyle aktualne, o ile zapewnia rzeczywistą

12 I. Iwasiów, Wstęp..., s. 10-11.

13 C. Amorós, Prólogo, do: Asunción Oliva Portolés, La pregunta por el sujeto en la teoría feminista. El debate filosófico actual, Madrid 2009, s. 12.

14 Por. F. Collin, É. Pisier, E. Varikas, Les Femmes de Platon à Derrida: anthologie critique, Paris 2011, passim. 
przestrzeń oddziaływania dla tysięcy kobiecych głosów i tekstów pisanych w wiekach dawnych. Ta strategia „odzyskiwania” pisarek, mecenasek i innych kobiecych postaci, które czynnie uczestniczyły w życiu kulturalnym, pozwala współcześnie tworzącym kobietom skonfrontować swoją twórczą tożsamość - lub chociażby samą obecność - z tym, co działo się w przeszłości w przestrzeni kreowanej przez kobiety. Teraz konfrontacja ta może być oparta na identyfikacji. Historia kobiet, rozumiana jako dyscyplina naukowa, przyniosła konieczność przemyślenia na nowo znaczenia takich słów, jak „autorka”, „pisarka”, „kanon” czy „literatura piękna”. Wymusiła również weryfikację procesów historycznych i ich chronologii, wprowadzenie nowych obszarów problemowych, nową interpretację znaczeń przestrzeni symbolicznych, w których w sposób czynny, a nie bierny funkcjonowały/funkcjonują kobiety. Te przesłanki przyświecały feministkom akademickim właściwie od lat siedemdziesiątych, co trafnie oddaje myśl Ann G. Gordon, Mari Jo Buhle i Nancy Shrom Dye (1976: 89):

Uczymy się, że wpisywanie kobiet $\mathrm{w}$ historię z konieczności pociąga za sobą redefinicję i rozciągnięcie tradycyjnych pojęć historycznej doniosłości w taki sposób, by włączyć zarówno osobiste, subiektywne doświadczenie, jak i działalność publiczną oraz polityczną. Nie będzie przesadą, jeśli zasugerujemy, że pomimo początkowych rozterek, metodologia ta implikuje nie tylko nową historię kobiet, ale także nową historię ${ }^{15}$.

Przez długi czas jednak osiągnięcia tej dyscypliny pozostawały na obrzeżach historii „uniwersalnej”, funkcjonując w najlepszym wypadku jako ciekawy dodatek do badań głównego nurtu, co w konsekwencji doprowadziło do powtórnej alienacji twórczości artystycznej

15 A.G. Gordon, M.J. Buhle, N.Sh. Dye, The Problem of Women's History, w: Liberating Women's History. Theoretical and Critical Essays, ed. B. Caroll, Urbana - Chicago 1976, s. 89. 
kobiet i badań im poświęconych poprzez zamknięcie ich $\mathrm{w}$,jednopłciowym getcie" (single-sex ghetto), z którego mówią kobiety ${ }^{16}$.

Przejście od historii kobiet do historii gender pozwoliło przezwyciężyć w znacznej mierze dialektyczną perspektywę binarnych opozycji i w rezultacie „wytłumaczyć niejednolite doświadczenia i społeczne praktyki w świetle różnorodnych tożsamości płci kulturowej jej protagonistek i protagonistów" ${ }^{17}$. W tym samym stopniu wprowadzenie do badań kulturowych i literaturoznawczych pojęcia relacji między „tym, co kobiece”, a „tym, co męskie”, umożliwiło dostrzeżenie różnorodności modeli kobiecości w ramach kontekstów historycznych i kulturowych. Kategoria gender pozwoliła na zaznaczenie relacyjnego charakteru normatywnych definicji kobiecości i męskości. Okazała się także użytecznym terminem analitycznym służącym podkreśleniu zasadniczo społecznego nacechowania rozróżnień płciowych, co pozwalało odciąć się od zagrożeń esencjalizmu i biologicznego determinizmu, pojawiających się przy operowaniu pojęciami „płci” czy „różnicy płciowej”. Niemniej dopiero ostatnie dekady wraz z tzw. powrotem podmiotu w badaniach filozoficznych, społecznych, historycznych i literaturoznawczych, zagwarantowały stałe miejsce takiej perspektywie owych badań, która zwraca się ku doświadczeniom kobiecym i odczytuje je w ramach własnych metodologii, a tym samym konstytuuje je jako prawomocny przedmiot badań, uznając je równocześnie za reprezentatywne głosy danej epoki. W ten sposób kobiety odzyskały swoją podmiotowość.

$\mathrm{W}$ badaniach nad literaturą kobiecego autorstwa tworzoną w wiekach dawnych kluczowe okazuje się ujęcie interdyscyplinarne, pozwalające stworzyć przestrzeń do dialogu między badaniami filologicznymi, historią społeczną i historią kultury oraz perspek-

16 Por. M. Jehlen, Archimedes and the Paradox of Feminist Criticism, „Signs” 6 (1981), s. 575.

17 G. García González, La experiencia de la mujer hecha memoria, w: Espacios visibles. Espacios invisibles. Mujer y Memoria en la Salamanca del Siglo XVI (selección documental), ed. G. García González, M.L. Prado Herrera, Salamanca 2006, s. 21. 
tywą badań genderowych. Ów dialog, postulowany przez badaczki hiszpańskie, m.in. przez Iris M. Zavalę ${ }^{18}$ i Myriam Díaz-Diocartez ${ }^{19}$, nawiązuje do znanych koncepcji wielogłosowości, cudzego słowa i dialogiczności Michaiła Bachtina, wypełniając jednocześnie lukę $\mathrm{w}$ analizach rosyjskiego literaturoznawcy poprzez wprowadzenie kategorii różnicy płci jako ko-konstytutywnej dla każdego procesu komunikacji międzyludzkiej. Położenie nacisku na kulturowo rozumianą różnicę płci stanowi podłoże również dla analiz takich badaczek historii, jak Joan W. Scott ${ }^{20}$, Natalie Z. Davis ${ }^{21}$ czy Mary Nash ${ }^{22}$. Siła takiego ujęcia interdyscyplinarnego wynika $\mathrm{z}$ faktu wzięcia pod uwagę aporii wpisanych w badania nad kulturą wieków dawnych przy użyciu nowoczesnych i ponowoczesnych kategorii analitycznych, w tym kategorii gender, przede wszystkim niebezpieczeństwa anachronizmu - przypisywania kobietom żyjącym w epokach dawnych współczesnej świadomości (np. przynależności do zbiorowości kobiet), a także ahistorycznych sposobów myślenia i postępowania (np. rewindykacji praw jednostki). Kolejnym zagrożeniem jest interpretacja w duchu finalizmu (celowego wyjaśniania procesów historycznych), funkcjonalizmu i biografizmu. Osiągnięcia literac-

18 I.M. Zavala, Las formas y funciones de una teoría crítica feminista. Feminismo dialógico, w: Breve historia feminista de la literatura española (en lengua castellana), t. 1: Teoría feminista: discursos y diferencia, ed. I.M. Zavala, M. Díaz-Diocartez, Barcelona 1993, s. 27-76; eadem, El canon, la literatura y las teorías feministas, w: Breve historia feminista de la literatura española (en lengua castellana), t. 1: Teoría feminista..., s. 9-20.

19 M. Díaz-Diocartez, „La palabra no olvida de donde vino”. Para una poética dialógica de la diferencia, en: Breve historia feminista de la literatura española (en lengua castellana), t. 1: Teoría feminista: discursos y diferencia, ed. I.M. Zavala, M. Díaz-Diocartez, Barcelona 1993, s. 77-124.

20 J.W. Scott, Gender as a useful Category of Historical Analysis, „American Historical Review” 91 (1989), nr 5, s. 1053-1075; eadem, Gender: Still a Useful Category of Analysis?, „Diogenes”, 57 (2010), s. 7-14.

21 N.Z. Davis, Gender and Genre: Women as Historical Writers, 1400-1820, „University of Ottawa Quarterly” 50 (1980), nr 1, s. 123-144; eadem, Women and the World of Annales, „History Workshop Journal” 33 (1992), s. 121-137.

22 M. Nash, Historia, retos y movimientos, Barcelona 2004. 
kiej krytyki feministycznej i historii kobiet w odzyskiwaniu głosów i genealogii pisarek są trudne do przecenienia. W wielu odczytaniach wczesnonowożytnych tekstów kobiecego autorstwa nie udało się uniknąć wspomnianych błędów, przypisując autorkom doby renesansu i baroku romantyczną wrażliwość czy współczesny system wartości i sposób rozumowania. Jednym z bardziej jaskrawych przykładów tego rodzaju nadużyć interpretacyjnych jest „użycie” postaci meksykańskiej poetki barokowej Juany Inés de la Cruz jako pierwszej emancypantki czy zaangażowanej politycznie ikony ruchu LGBTIQ ${ }^{23}$. Juana Ramírez de Asbaje (1651-1695) pełniła wiele różnych ról społecznych: najpierw była damą dworu, później zakonnicą, pisarką i poetką. Jako Juana Inés de la Cruz stała się postacią literacką, Dziesiątą Muzą Meksyku i rara avis parnasu literackiego Wicekrólestwa Nowej Hiszpanii. Jako pisarka stanowiła, i stanowi nadal, niemałe wyzwanie dla krytyki literackiej z kilku powodów: ze względu na formalną złożoność jej twórczości, specyficzny kontekst społeczno-kulturowy wyznaczający znaczenia bycia pisarką, zakonnicą i kobietą $\mathrm{w}$ ramach siedemnastowiecznego społeczeństwa kolonialnego oraz bardzo ograniczone źródła dotyczące jej życia i aktywności literackiej. Wiersze Juany Inés stały się przedmiotem zagorzałej debaty dotyczącej ich funkcji w kontekście danej kultury literackiej oraz wyrażanej w nich ideologii i celów, jakim miały służyć. Przy okazji rozwinęła się polemika wokół formowania się kobiecego podmiotu lirycznego. Właśnie to niejednoznaczne użycie podmiotu lirycznego - wynikające z konwencji literackich epoki, ale jednocześnie podejmujące pewnego rodzaju grę o charakterze retorycznym - stało się przyczynkiem do licznych nadinterpretacji, nadających twórczości tej autorki charakter postromantycznego manifestu wolności uczuciowej i politycznej. Identyfikacja podmiotu

23 Temat ten szczegółowo analizuje Julia Lewandowska w artykule Sor Juana Inés de la Cruz y la crítica literaria feminista: contribuciones y controversias, „Itinerarios. Revista de estudios lingüísticos, literarios, históricos y antropológicos” 15 (2012), s. 43-66. 
lirycznego z autorką tekstu, nieuwzględnianie złożoności konwencji literackich i strategii retorycznych, pominięcie znaczenia materialności tekstów w procesie ich produkcji i cyrkulacji (roli edytorów, mecenatów i cenzorów), czy wreszcie argumentacja z klucza lingwistycznego determinizmu, gdzie użycie rodzaju żeńskiego uznane jest za dowód na solidarność autorki z czytelniczkami we wspólnym doświadczeniu opresji, są przykładami zagrożeń, jakie niesie ze sobą nieumiejętne, czyli historycznie i kulturowo nieumiejscowione użycie optyki feministycznej i gender przy badaniach nad twórczością literacką kobiecego autorstwa. Jedynie wyjście od głębokiej znajomości kontekstu społeczno-kulturowego i literackiego oraz użycie kategorii gender jako relacyjnej, w ścisłej zależności od innych parametrów różnicujących, takich jak przynależność etniczna, rasowa, klasowa, wyznaniowa czy identyfikacja seksualna, pozwala zobaczyć, jak poszczególne głosy i doświadczenia twórcze kobiet uwikłane są w szereg zależności z głosami męskimi oraz instytucjami zarządzającymi produkcją, cyrkulacją i cenzurą tekstów.

Podsumowując - zgodnie z myślą Mary Nash i Joan W. Scott, można skonstatować, iż gender pozostaje użyteczną kategorią analiz historycznoliterackich zawsze wtedy, gdy utrzymuje się w krytycznej relacji do binarnych kategorii „kobieta”/,mężczyzna” i „kobiecość”/ „męskość", jak i do swojej własnej funkcji tworzenia społecznych dynamik opartych na różnicy seksualnej. W tym znaczeniu ujęcie dialogiczne pozwala wyjść poza programowe i metodologiczne ramy badań feministycznych, w których „kobieta” i „mężczyzna” przedstawieni są jako kategorie stałe i domknięte, służące jedynie do opisu różnych ról społecznych, jednak nieprowadzące do ich krytycznego odczytania. Podkreślenie nierozerwalnej zależności między kategorią gender a kontekstem społeczno-historycznym otwiera możliwość pytań o to, w jaki sposób znaczenia płci kulturowej i biologicznej są wytwarzane i powtarzane we wzajemnej relacji i jak odbijają się one w kulturze danego momentu historycznego. W ramach takiej perspektywy badawczej analizuje się nie tyle różne role społeczne przypisane kobietom i mężczyznom, co samą konstrukcję różnicy seksualnej. W ten sposób kategorie płci seksualnej i kulturowej kon- 
stytuują się wzajemnie w ramach procesu historyczno-kulturowego. Jak syntetycznie ujmuje to Joan $\operatorname{Scott}^{24}$ w Gender: Still a Useful Category of Historical Analysis?, aktualizując swoje stanowisko z 1986:

W procesie [historyczno-kulturowym] to gender tworzy znaczenie płci i różnicy seksualnej, to nie płeć determinuje znaczenie nadawane gender. Jeśli tak to wygląda, [...] nie tylko nie ma różnicy między płcią a gender, ale także gender jest kluczem dla [zrozumienia] kategorii płci.

Użycie gender jako kategorii relacyjnej i warunkowej, zgodnie z propozycją m.in. Glorii Garcii González ${ }^{25}$, pozwala uniknąć „pokusy mówienia o kobietach jako zbiorowości społecznie zmarginalizowanej”, co w ostateczności prowadzi jedynie do umocnienia dynamiki między tym, co centralne, a tym, co podporządkowane. Co więcej, ujmuje różnicę seksualną jako akt performatywny czy też dialogiczny wobec konkretnego aktu komunikacji. W takich ramach teoretycznych akt mowy odzwierciedla różne pozycje tego, co się mówi i kto to mówi, jak zaznacza Collin:

w każdej wypowiedzi znajduje się, w zawieszeniu i zakwestionowaniu, to, co chce powiedzieć mężczyzna, i to, co chce powiedzieć kobieta, czy to w przemocy konfrontacji, czy też $\mathrm{w}$ pokojowym zrozumieniu: różnica między płciami jest jednocześnie aktem politycznym, etycznym i symbolicznym ${ }^{26}$.

Utrzymanie zatem otwartego charakteru kategorii gender, która pyta o formy i znaczenia oraz o konteksty reprodukowania tych znaczeń, okazuje się skutecznym sposobem na to, by zachować jej ważność dla badań historycznych i literackich.

Rozważania te wpisują się, jak sądzimy, w aktualne wciąż pytania, jak analizować kobiece teksty dawne. Wiele wskazuje na to, że wy-

24 J. Scott, Gender: Still a Useful Category..., s. 14

25 G. García González, La experiencia de la mujer..., s. 17-34.

26 F. Collin, Diferencia y diferencio: la cuestión de las mujeres en filosofía, w: Historia de las mujeres. Mujeres, creación y representación, t. 5, red. G. Duby, M. Perrot, Madrid 2000, s. 354. 
pracowano już metodologię, która pozwala rzetelnie, $\mathrm{z}$ różnych perspektyw, bez ideologicznych emocji i dyskusji wokół pojęcia gender, za to z uwzględnieniem szerokiego kontekstu historycznego, opisać bierne i czynne uczestnictwo kobiet w procesie tworzenia literatury.

\section{Bibliografia}

Amorós C., Prólogo, w: Asunción Oliva Portolés, La pregunta por el sujeto en la teoría feminista. El debate filosófico actual, Madrid 2009, s. 11-20.

Collin F., Différence et différend, la question des femmes en philosophie, w: Histoire des femmes en Occident, t. 5, red. G. Duby, M. Perrot, Paris 1992, s. 243-374.

Collin F., Praxis de la diferencia. Liberación y libertad, Barcelona 2006.

Davis N.Z., Gender and Genre: Women as Historical Writers, 1400-1820, "University of Ottawa Quarterly" 50 (1980), nr 1, s. 123-144.

Davis N.Z., Women and the World of Annales, „History Workshop Journal” 33 (1992), s. 121-137.

Díaz-Diocartez M., „La palabra no olvida de donde vino”. Para una poética dialógica de la diferencia, w: Breve historia feminista de la literatura Española (en lengua castellana), t. 1, Teoría feminista: Discursos y diferencias. Enfoques feministas de la literatura española, Barcelona 1993, s. 77-124.

García González G., La experiencia de la mujer hecha memoria, w: Espacios visibles. Espacios invisibles. Mujer y Memoria en la Salamanca del Siglo XVI (selección documental), ed. G. García González, M.L. Prado Herrera, Salamanca 2006, s. 19-35.

Gilbert S., Gubar S., No Man's Land: Sex Changes, New Haven 1991.

Gilbert S., Gubar S., The Madwoman in the Attic: The Woman Writer and the Nineteenth-Century Literary Imagination, New Haven 1979.

Gordon A.D., Buhle M.J., Dye N.Sh., The Problem of Women's History, w: Liberating Women's History. Theoretical and Critical Essays, ed. B. Caroll, Chicago 1976, s. 75-93.

Iwasiów I., Wstęp, w: Prywatne/publiczne. Gatunki pisarstwa kobiecego, red. I. Iwasiów, Szczecin 2008, s. 7-11.

Jehlen M., Archimedes and the Paradox of Feminist Criticism, „Signs” 6 (1981), s. $575-561$.

Kramarae Ch., Coming to Terms with Women's Language, w: International Encyclopedia of Communications, ed. E. Barnouw, t. 1-2, New York 1989, s. 157-60.

Lewandowska J., Sor Juana Inés de la Cruz y la crítica literaria feminista: contribuciones y controversias, „Itinerarios. Revista de estudios lingüísticos, literarios, históricos y antropológicos” 15 (2012), s. 43-66. 
Nash M., Historia, retos y movimientos, Barcelona 2004.

Partyka J., Żona wyćwiczona. Kobieta pisząca w kulturze XVI i XVII wieku, Warszawa 2004.

Penelope J., Unlearning the Lies of the Fathers' Tongues, New York 1990.

Rivera Garretas M. M., Nombrar el mundo en femenino: Unos ejemplos del Humanismo y Renacimiento, w: La conjura del olvido. Escritura y Feminismo, ed. N. Ibeas, M. Ángeles Millán, Barcelona 1997, s. 89-106.

Scott J.W., Gender as a Useful Category of Historical Analysis, „American Historical Review" 91 (1986), 5, s. 1053-1075.

Scott J.W., Gender: Still a Useful Category of Analysis?, „Diogenes” 57 (2010), s. 7-14.

Showalter E., Krytyka feministyczna na bezdrożach. Pluralizm a krytyka feministyczna, „Teksty Drugie”, nr 4/5/6 (22/23/24) 1993, s. 115-146.

Spender D., Man Language, London 1984.

Zavala I.M., Las formas y funciones de una teoría crítica feminista. Feminismo dialógico, $\mathrm{w}$ : Breve historia feminista de la literatura española (en lengua castellana), t. 1, Teoría feminista: discursos y diferencia, ed. I.M. Zavala, M. Díaz-Diocartez, Barcelona 1993, s. 27-76.

Zavala I.M., El canon, la literatura y las teorías feministas, w: Breve historia feminista de la literatura española (en lengua castellana), t. 1, Teoría feminista: discursos y diferencia, ed. I.M. Zavala, M. Díaz-Diocartez, Barcelona 1993, s. 9-20. 